\title{
Education for Creativity: Motivation and Learning
}

\section{Luke Strongman}

Open Polytechnic of New Zealand, New Zealand

\begin{tabular}{|c|c|}
\hline & ABSTRACT \\
\hline $\begin{array}{l}2022 \text { Research Leap/Inovatus Services Ltd. } \\
\text { All rights reserved. } \\
\text { DOI: } 10.18775 / \text { jibrm.1849-8558.2015.72.3003 } \\
\text { URL: } \\
\text { https://doi.org/10.18775/10.18775/jibrm.1849- } \\
8558.2015 .72 .3003 \\
\end{array}$ & $\begin{array}{l}\text { This presentation explores motivation as it is related to teaching and to the workplace. As Yoshida } \\
\text { et al., suggest, motivation is related to a variety of educational outcomes which include curiosity, } \\
\text { persistence, motivation and performance ( } 2008, \text { p. 1401). As such it is an internal state that may } \\
\text { be effected by external factors which in turn "arouse, direct and sustain behaviour" (Tan, 2009, } \\
\text { p. 156). Motivation is also related to calibration. As Hallinan states, "Calibration measures the } \\
\text { difference between actual and perceived ability. If you're as good as you think you are, then you } \\
\text { are said to be well calibrated. If you are not as good as you think you are, then you are said to be }\end{array}$ \\
\hline $\begin{array}{l}\text { Keywords: } \\
\text { Education, Motivation, Teaching. }\end{array}$ & $\begin{array}{l}\text { poorly calibrated" (Hallinan, } 2009 \text {, p. } 155 \text { ). Consequently in the educational enterprise (or in any } \\
\text { learning task) it is preferable that the learner starts of in a well calibrated condition. This will } \\
\text { entail a reasonably realistic view of their learning competencies and be less likely to result in } \\
\text { demotivation from negative feedback should these learning competencies by too widely } \\
\text { calibrated. Secondly, a well calibrated individual is more likely to respond to the conditions of } \\
\text { optimal motivation that are possible in the learning situation of a self-determined learner. Related } \\
\text { to calibration is the fact that students and employees can be motivated when they do not perceive } \\
\text { contingencies or opportunistic incentives or barriers between actions and outcomes (Yoshida et } \\
\text { al., 2008, p. 1401). Diminution of autonomy may lead to mal-adaptive consequences (Deci, 1996, } \\
\text { p. } 31 \text { ). Whilst in everyday life it serves as justification for service and job performance, morally } \\
\text { it is not in itself self-justificatory. In the teaching context, Gardner and Lambert (1972) describe } \\
\text { motivation as persistence that is shown by teachers and learners in the learning environment } \\
\text { towards achieving a learning goal. In both the teaching and business context a distinction can be } \\
\text { made between intrinsic motivation (behaviour for its own sake) and extrinsic motivation } \\
\text { (behaviour as a means to some external reward) (Bektas-Cetinkaya and Oruc, 2011, p. 72). }\end{array}$ \\
\hline
\end{tabular}

\section{Introduction}

An integral part of any learning requires motivation for that learning to take place. Motivation is not only a feature of student learning but also of classroom instruction and moreover the interactive teaching techniques that are part of the classroom learning experience. As Pintrich states, motivation is derived from the Latin verb movere, meaning 'to move' (2003, p. 699). As Dykstra et al. suggest, "Students who are intrinsically motivated engage in an activity for enjoyment, to learn, and/or out of a sense of accomplishment, while extrinsic motivation arises out of a need to be rewarded, for example with a higher grade, or to avoid a penalty." (2011, p. 2). The "control theory' of motivation assumes that people are compelled to act from the "promise of reward or the threat of punishment" (1996, p. 1). This is consistent with the behaviourist concept of stimulus and response, however peoples' and particularly educationists' cognitive complexity reveals that there is far more to motivation in learning than 'sticks and carrots'. There is continued debate of whether there is a motivational 'ethic' but in as much as motivation is an inherent part of human nature, everyone has a right to find motivation - a willingness if not inherent justification to act towards a particular goal. Although people are conditioned by their environment there is a difference between acting for others and acting from 'free will' in accordance with one's own volition. As Deci suggests (1996, p. 2).

When autonomous, people are fully willing to do what they are doing, and they embrace the activity with a sense of interest and commitment. Their actions emanate from their true sense of self, so they are being authentic. In contrast, to be controlled means to act because one is pressured. When controlled, people act without a sense of personal endorsement. Their behaviour is not an expression of the self, for the self has been subjugated to controls.

However, what is widely known is that there is a significant correlation between intrinsic motivation and academic achievement (Goldberg and Cornell, 1998). Conversely as Deci explains, "[m]otivation requires that people see a relationship 
between their behaviour and desired outcome, and instrumentalities are the linkages that allow people to see these behaviour-outcome relationships" (Deci, 1996, p. 59). This linkage can in some circumstances (more remotely) be economic or intrinsic (by affective bonds). Motivation and its associated affective elements is one of the most important factors in students' learning and academic performance which is implicit but seldom formalised within teaching pedagogy. Motivation is commonly defined within the teaching and learning environment as the inter- relation of motivational beliefs (the inherent value of tasks) with achievement emotions (such as enjoyment, boredom or anxiety) and academic performance and hence also in the workplace (Artino et al., 2010, p. 123). Motivation has given some educators pause to reflect on the appropriate theories of mind which might encompass motivation in the teaching and learning process. In this respect the main challenge to the 'information processing' model of learning has come from the necessity to include more subtle emotions and intentional beliefs in the learning process. Social cognitive theory holds that human functioning results from 'triadic, dynamic and reciprocal' inter-relation of behaviours (individual actions and choices) with personal factors (beliefs, intentions, and expectations) and factors in the physical and social environment (Artino et al., 2010, p. 1204). According to this model task value is balanced with selfefficacy. Task value involves students' beliefs of how relevant or interesting an activity (such as a course module or a qualification) is to them, whereas academic self-efficacy involves beliefs about the inter-relation of student's selfassessment and outside reinforcement of their ability to perform academic tasks (Artino et al., 2010, p. 1205). As Botkin et al., suggest academic learning requires a shift from maintainence learning (acquiring knowledge do deal with cuurent issues) to dynamic learning (requiring development of new ideas) and this experience can be in itself highly motivational (1979). By comparison the control-value theory of motivation defines achievement related emotions as 'internal affective rewards' which are associated with completion of learning tasks. This emotional self-evaluation may vary from enjoyment associated with new learning, to anxiety in completing a specific task to frustration and disappointment if the result is disproportionate to the effort involved (Artino et al., 2010, p. 1205). Consequently motivational beliefs defined in terms of task value, self efficacy are correlated with course or learningactivity elated enjoyment and anxiety in learning activities (Artino et al., 2010, p. 1205). Task value beliefs are therefore reasonably accurate predictors of learning satisfaction or boredom. If a learning task or course is believed to be useful, relevant and important students are more likely to feel motivated to task completion by their enjoyment of it (Artino et al., 2010, p. 1210).

\subsection{Emotion and Motivation}

Emotion and affect are described as 'feeling[s], emotion[s] or desire[s], especially leading to action' (Sikhwari, 2007, p. 523). Students who are confidant of their learning and of their learning environment are less likely to be disadvantaged by experiencing the inhibitory effects of anxiety in the learning performance. Enjoyment of the learning process is positively associated with successful educational outcomes whereas boredom and anxiety are negatively associated with academic performance. Consequently, it behoves teachers to provide motivations inspiration in learning environments as well as subject content and the application of teaching pedagogy wherever possible. It is useful for teachers to find ways to enhance the inter-relation between self-concept, motivation and academic achievement (Sikhwari, 2007, p. 520). Understanding of motivation takes place in the context that most teaching pedagogies emphasise cognitive factors at the expense of affective factors. In this context intelligence is seen as the prime contributor to student success however, increasingly the affective component of learning - what teachers and students feel about themselves in relation to the learning task is increasingly important. Increasingly affective factors play a critical role in the motivation, attitude and self-concept of students. Higher achievement is associated with optimal attitude and positive self-concept and efficient use of study time whereas students who have a negative attitude may impose limitations on their achievements (Sikhwari, 2007, p. 521). Whether students see themselves of having ability of feeling successful or failing, of being accepted or rejected, have having positive emotions in the learning environment - such as happiness, joy of learning, self-satisfaction, reciprocity - or whether students feel defeated influences aspects of behaviour or learning (Sikhwari, 2007, p. 521). Sikhwari suggests that the main influence that high motivation has on students is in giving them the ability to effectively select and persist in information processing (2007, p. 522). If a student is motivated and interested then there is an increase in depth of processing, memory, knowledge acquisition, attention and comprehension (Sikhwari, 2007, p. 522).

\subsection{Self-concept and Motivation}

A student or employee's self-concept is central to their understanding and perception of the learning process, it refers to a set of ideas that a student may believe about him or herself which exists on a continuum of positive and negative effect. As (Teoh et al., 2009, p. 721) suggest, factors related to personal beliefs include: "significance of learning, confidence, interest, efforts, family support, independence, self-direction, teacher's attention". In this context, although affect can have a large effect on student motivation it is more dangerous when unaccompanied by conscious cognition and the possibility for remediation through the introduction of motivational elements which improve it. Secondly, positive and negative affect may 
or may not be related to a student's actual potential for educational performance and from a third-part objective perspective its influence may thus be over-rated. A student can be negatively motivated and pass an examination and positively motivated yet fail - motivation is one intervening factor in a complex inter-relation of effects, including mastery of subject content, experience and self-reliance.

A self-concept is an evolving factors in the construction of learners educational lives, it is neither finite nor static and may change on a ratio of positive or negative influence depending on the learners values, thoughts and intentions, the hospitability of the learning environment and prevailing organisational culture and circumstances (Sikhwari, 2007, p. 523). Motivation also involves personality and will as is seen as a driving force in closing the gap between current and future states of knowledge involving skill acquisition and qualifications. It is not inherently something that is "done to people rather is something that people do" (Deci, 1996, p. 21). It is also an intrinsic factor in workplace organisation as well in the personal psychological fabric of students' lives.

Sikhwari suggests that it comprises a set of dependent/independent variables in relationships between the learning and the learning activity which account for the persistence and direction of a learner's behaviour if all other factors such as aptitude, skill, understanding, intelligence and environmental constraints are held constant (Sikhwari, 2007, p. 523). Furthermore, any learning-teaching situation may be characterised by what may be termed "autonomous dependence" (Deci, 1996, p. 90). This differs markedly from overly-controlled environments which are characterised by "coerced or controlled dependence" which may be amotivational (Deci, 1996, p. 90). Motivation is also related to attitude as an underlying constant in the formulation of a learning disposition. A more precise definition of attitude is offered as "[m]ental and neural states of readiness, organised through experience, exerting a directive or dynamic influence on a person's response to objects and relations" (Sikhwari, 2007, p. 524). As such attitude is seen as a concept which might be real or imagined and involves a cognitive, evaluative orientation of an individual (Sikhwari, 2007, p. 524). Attitude differs from motivation in so much as the former concerns a general tendency to behave in a particular way towards a task whereas the latter is concerned with providing the reason or driving force towards accomplishing the task (Sikhwari, 2007, p. 524).

Individuals who have relatively high stress and feelings of discomfort at University but a lower sense of control are more likely to experience a lowered sense of well-being and correspondingly may feel limited enjoyment and motivation (Gavala and Flett, 2005, p. 52). In comparison in situations where people report a higher sense of academic control with higher comfort from the environment there is correspondingly higher well-being. People desire to be a causal agent in managing their own learning (Deci, 1996, p. 94). Interestingly Gavala and Flett found no moderating effects of cultural identity on motivation (2005). If people are presented with a comfortable working environment that is culturally congruent to them then there are corresponding increases in psychological well-being and academic enjoyment and motivation (Gavala and Flett, 2005, p. 52). Factors contributing to academic success include a.) maintaining good working relationships (or at least a sound relationship with one other), and b.) having solid family support. Motivation is related to attitude in so far as evaluation of experience as positive or negative may interact with motivation to continue change or discontinue a particular task. Academic achievement, for example, may be its own reward or it may be a means to further reward such as qualification for employment. However, motivation becomes particularly important when equity issues such as socioeconomic status, low incomes, low education, produce limited opportunities for development. In such situations where there are few external drivers of motivation and negative stimulants for attitude, intrinsic motivation becomes far more important. Extrinsic rewards, when they are part of educational development, need to be equitable (Deci, 1996, p. 55).

Choice is also relevant for motivation. If an individual chooses to be involved in a particular activity for curiosity or intrinsic reasons they are more likely to value it (Shroff et al., 2008, p. 114). Coping behaviour is also predicated on personal efficacy in relation to task engagement, if personal efficacy in task engagement is seen as higher than people will be more motivated, if it is seen as lower then demotivation may result (Shroff et al., 2008, p. 121). Coupled with intrinsic motivation, extrinsic motivation such as teacher's attitudes or instructional design quality are important but these factors are one pedagogical overlay on stimulating self- regulation among students which may include three factors: "personal functioning by goal setting, self-evaluation in academic performance" and utilising the "learning environment by seeking information and assistance" (Teoh et al., 2009, p. 712).

\subsection{Concepts in Academic Motivation}

Curiosity contributes to motivation in so much as it is one driver of persistence in learning and performance (Yoshida et al., 2008 , p. 1401). The antithesis of motivation is the situation of 'learned helplessness' which can arise when people are exposed to uncontrollable stresses which condition them to fail to recognise and escape from controllable stresses - causing demotivation and even in some cases, depression (Yoshida et al., 2008, p. 1401). Conversely the motivation for accomplishment of learning tasks can be defined as the psychological propensity for pleasure and satisfaction 
following successful task completion. Classroom motivation is also related to certain instructor/teacher characteristics such as "fairness, caring, enthusiasm, consistency and impartiality" (Dykstra et al., 2011, p. 2). Motivational values such as a desire to learn, personal incentives (intrinsic and extrinsic) and striving for excellence may be affected from such conditions as: Interest, learning from others, taking responsibility for learning, intrinsic and extrinsic task and social rewards (Yoshida et al., 2008, p. 1402). While completed tasks are seen as more pleasant and incomplete tasks as less pleasant, tasks recall is higher for completed tasks than incomplete tasks. Moreover, instructors who maintained highly structured, organized and outcome-focused lessons are more likely to inspire motivational learning confidence in students (Dykstra et al., 2011 , p. 2). For students of lower ability, completion of lowlevel tasks is more rewarding than attempting to complete higher level tasks which motivate other groups (Yoshida et al., 2008, p. 1410). Tan suggests that student achievement is attributable to both environmental and genetic conditions (2009, p. 156) however it is not possible to improve the learning performance of someone who is not motivated.

As Wilson suggests, motivation explains behaviour and actions (Wilson, 2009, p. 272). It is defined as being "the force which starts and sustains our activities towards achieving our goals" (Wilson, 2009, 272). If a performance orientated student has high motivation without an internal interest then it is more likely for them to adopt approaches to learning that are 'surficial' (Wilson, 2009, pp. 278-279). This emphasises the need in some learning situations for intrinsic goal setting rather than over-reliance on external goal setting (Wilson, 2009, pp. 278-279). Surface learning is thought to be a characteristic of 'performance avoidance students; whereas performance approach students adopt a more strategic approach $t$ learning in which intellectual achievement is valued and obligations are intended to be fulfilled (Wilson, 2009, p. 279).

According to Dornyei and Shekan (2003) motivation describes three factors: 1.) why they do something, 2.) how long they do it for, 3.) how hard to pursue it. However, because people are infinitely complex there is no one definitive path to peoples' motivations. Putting money into consideration in motivational contexts is more complex and is not in itself to be considered an entirely beneficial ingredient in the learning process. As Deci explains, "When people say that money motivates, what they really mean is that money controls. And when it does, people become alienated - they give up some of their authenticity - and they push themselves to do what they think they must do" (1996, p. 29). Consequently monetary motivation is thought to undermine autonomy and volition in some circumstances. At the level of extrinsic reward Adair also points to the shortcomings of money as a motivational tool, "At best money is a crude measure of the value of work. Is a pop star really worth a thousand times more than a brain surgeon?" (2006, p. 113).

Diminution of autonomy may lead to mal-adaptive consequences (Deci, 1996, p. 31). Whilst in everyday life it serves as justification for service and job performance, morally it is not in itself self-justificatory. In the teaching context, Gardner and Lambert (1972) describe motivation as persistence that is shown by teachers and learners in the learning environment towards achieving a learning goal. A distinction can be made between intrinsic motivation (behaviour for its own sake) and extrinsic motivation (behaviour as a means to some external reward) (Bektas-Cetinkaya and Oruc, 2011, p. 72). Many peoples' motivations may be seen as being on a continuum between self-determined and controlled motivation (Bektas- Cetinkaya and Oruc, 2011, p. 72). However, little attention is often made to the environmental factors of motivation be they physical or social in effect. However, a study by Clemens (2008) revealed that students' socioeconomic status has a large effect on academic achievement and that motivationally supportive environments are positively related to academic achievement (Bektas-Cetinkaya and Oruc, 2011, p. 72).

\subsection{A Summary of Different Theories of Motivation}

As Wilson suggests, motivation is the term used to explain why we act in certain behavioural patterns at given times, and is a "force which starts and sustains our activities towards goal achieving" (Wilson, 2009, p. 272). There are four major theories of motivation. Attribution theory suggests that our actions are the result of making sense of our environment, the search for causes to perceptions, feelings and events creates a behavioural dynamic of socially constructed reality (Wilson, 2009 , p. 272). In comparison, expectancy value theory suggests that the amount of motivation or effort for a task is dependent on the expectant value of success. The fact that individuals calibrate themselves or set gaols based on interpretations of past achievements is the basis for self-efficacy theory. Fourthly, goal orientations explain how we view success give orientation towards a particular activity (Wilson, 2009, p. 272). The mastery of goal expectation is based on a desire for increased understanding which is more likely to occur in learning environments in which students receive sufficient feedback in response to learned competencies. There is also a distinction between performance approach goals and performance avoidance goals. Performance approach goals refer to orientation toward demonstrating high ability whereas performance avoidance goals orientation towards demonstrating low ability. In the education context overlycontrolling behaviour is thought to reduce choice, diminish autonomy and if applied in too rigid an environment lead to reduced motivation. As Deci suggests, "Deadlines, imposed goals, surveillance, and evaluations undermine intrinsic 
motivation. People experience them as being antagonistic to their autonomy, so these events drain people's sense of enthusiasm and interest in controlled activities." (1996, p. 31). However, if such controls are delivered in such a way to make them appealing, with corresponding intrinsic and extrinsic rewards, people may feel more motivated to accomplish them.

\subsection{Motivational Attitudes}

According to Pintrich there are four types of extrinsic motivational styles which are expressed on a continuum from externally influenced (learning environment controls) to internally influenced (self-controlled). These are: a.) external regulated by others according to constraints and rewards, $b$.) introjectors who internalise values but who are still externally controlled, c.) identification - more internal control and selfvalidation with learning values, d.) integration - high internal control and alignment with learning values (2003, p. 673).

According to Pintrich suspension of perceived control in some learning situations may valuable for students as it necessitates adaption to the learning task (2003, p. 673). If students fail they then are more likely to attribute it to a cause outside their control - thus teachers need to provide intrinsic motivational rewards that do not cause students to negatively externalise their learning task self-efficacy. As Deci suggests, "to be intrinsically motivated people need to perceive themselves as competent and autonomous; they need to feel that they are effective and self-determining." (1996, p. 86). However, in many situations student and learning environment stability rather than control is more important in predicting future outcomes from motivated behaviour although control is reflected in the difference between the learning gap in adaptive (shapeable) or unchanging levels of knowledge acquisition and intelligence (Pintrich, 2003, p. 673). Adair suggests there are eight principles of motivating others (2006, p. 109):

$\begin{array}{ll}\text { - } & \text { Be motivated yourself } \\ \text { - } & \text { Select people who are highly motivated } \\ \text { - } & \text { Set realistic and challenging targets } \\ \text { - } & \text { Remember that progress motivates } \\ \text { - } & \text { Create a motivating environment } \\ \text { - } & \text { Give recognition }\end{array}$

However, even if all other motivational factors are successful and students learn in optimal environments - external influences may undermine student engagement - these include family and employment commitments, personal and personal and cultural factors (Ross, 2010, p. 5). Overall however, whatever the characteristics of the learner, instructor or the environment motivation is the "attainment of a state of being" (Deci, 1996, p. 21).

\section{Conclusion}

Motivation is a central though under-researched factor in teaching and learning and workplace performance. It is a intrinsic characteristic of any learning process but is frequently over- looked in many pedagogical models of teaching practices. Motivation is inherently concerned with a 'desire to learn', it is the cognitive and affective elements that provides the drive to close the gap between one state of knowledge and another more advanced state in any learning practice. Motivation has both intrinsic and extrinsic causations and is often predicated on a mixture of self-determined and environmental conditions. It behoves any teacher both in contact and in distance education to design environments in which students are given the optimum conditions to flourish and realise their learning potential. Because of the combination of self-determined and extrinsic features of any motivational learning environment, motivation requires a form of learner-instructor interaction which is at least interested and self-sustaining and at best a fully engaging humanistic exchange of curriculum knowledge and ultimately within the workplace.

\section{Literature}

- Adair, J. (2006). Leadership and Motivation: The fiftyfifty rule and the eight key principles of motivating others. London: Kogan Page.

- Artino, A. R., La Rochelle, J. S. and Durning, S. (2010). Second-year medical students' motivational beliefs, emotions, and achievement. Medical Education, 44(12), 1203-1212.

- Bektas-Cetinkaya, Y. and Oruc, N. (2011). Effects of Socioeconomic Status and physical Learning Environment on Motivation of University Students. European Journal of Social Sciences, 21(1), 71-79.

- Botkin, J., Elmandjra, M. and Malitza, M. (1979). Bridging the human gap. Oxford: Pergamon Press.

- Clemons, T. L. (2008). Underachieving gifted students: A social cognitive model.

- Virginia: The National Research Center on the Gifted and Talented.

- Deci, E. L. (1996). Why we do what we do: Understanding self-motivation. Auckland: Penguin.

- Dornyei, Z. and Shekan, P. (2003). Individual differences in second language learning. In

- C. Doughty and M. Long (eds.), The Handbook of second Language Acquisition (pp. 589-630). Oxford: Blackwell.

- Dykstra, D. V., Moen, D. and Davies, T. (2011). Comparing student and faculty - perceptions related to academic freedom protection. Research In Higher Education Journal, 14, 27-37.

- Gardner, R. C. and Lambert, W. (1972). Attitudes and Motivation in Second Language Learning. Rowley: 
Newbury House.

- Gavala., J. R. and Flett, R. (2005). Influential Factors Moderating Academic Enjoyment/Motivation and Psychological Well-being for Maori university Students at Massey University. New Zealand journal of Psychology, 34(1), 52-57.

- Goldberg, M. D. and Cornell, D. I. (1998). The Influence of intrinsic motivation and self- concept on Academic achievement: a casual modelling investigation with Hong Kong tertiary students. British Journal of Educational Psychology, 68, 173188.

- Hallinan, J. T. (2009). Why We Make Mistakes: How We Look Without Seeing, Forget Things in Seconds, and Are All Pretty Sure We Are Way Above Average. New York: Random House.

- Pintrich, P. R. (2003). A Motivational Science Perspective on the Role of Student motivation in Learning and Teaching Contexts. Journal of Educational Society, 95(4), 667-686.

- Ross, C. (2010). Engaging distance students in learning: What matters to students, what motivates them and how can engagement in learning be fostered?. Lower Hutt: The Open Polytechnic of New Zealand.
- $\quad$ Shroff, R. H., Vogel, D. R. and Coombes, J. (2008). Assessing Individual-Level Factors Supporting Student intrinsic motivation in online discussions: A Qualitative Study. Journal of Information Systems Education, 19(1), 111-126.

- Sikhwari, T. D. (2007). The relationship between affective factors and the academic achievement of students at the University of Venda. South African Journal of Higher Education, 21(3), 520-536.

- Tan, S. (2009). Perceptions of students on factors in motivation to learn. E-Journal of New World Sciences Academy, 4(1), 155-167.

- Teoh, S. H., Koo, A. C. and Singh, P. (2009). Extracting factors for students' motivation in studying mathematics. International Journal of Mathematical Education in Science and Technology, 41(6), 711-724.

- Wilson, J. I. (2009). A two factor model of performance approach goals in student motivation for starting medical school. Issues in Educational Research, 19(3), 271-281.

- Yoshida, M. et al. (2008). Factors Influencing the Academic Motivation of individual College Students. International Journal of Neuroscience, 118(10), 1400 1411. 